\title{
De los consejos de guerra al Camarón. Respuestas represivas a las protestas sociales (1969-1973)
}

\author{
[From the war councils to the Camarón. \\ Repressive responses to social protests (1969-1973)]
}

\author{
Marianela Scocco \\ (ISHIR-CONICET/Universidad Nacional de Rosario, Argentina) \\ mariascocco@gmail.com
}

\begin{abstract}
Resumen
1969 fue un año bisagra por las movilizaciones callejeras que se produjeron en varias ciudades del país, así como por las respuestas que ellas generaron. El crecimiento de la actividad represiva estatal comprendió detenciones masivas y la reprimenda de diversas manifestaciones populares. Más aun, parte de esa actividad represiva adoptó un carácter clandestino a través de operaciones desplegadas por los servicios de inteligencia y los grupos paraestatales que llevaron adelante amenazas, atentados, secuestros, desapariciones y asesinatos. Sin embargo, en este artículo me centro en los mecanismos "legales" que utilizó la dictadura: los consejos de guerra y el "Camarón", examinando ambos dispositivos utilizados como respuestas represivas a las movilizaciones de fines de los años sesenta y principios de los setenta. Para su análisis, considero la articulación entre las disposiciones generales establecidas por leyes, decretos y reglamentos nacionales y la aplicación de dichas normas en Rosario, bajo jurisdicción del II Cuerpo de Ejército.
\end{abstract}

Palabras claves: Consejos de guerra Camarón - Protesta social - Represión.

\begin{abstract}
1969 was a year hinge for the street mobilizations that occurred in several cities of the country, as for the responses they generated. The growth of state repressive activity included mass arrests and the reprimand of various popular demonstrations. Part of that repressive activity adopted a clandestine nature through some operations deployed by intelligence services and parastatal groups, carrying out threats, attacks, kidnappings, disappearances and murders. However, in this article I focus on the "legal" mechanisms used by the dictatorship: the war councils and the "Camarón", examining both devices used as repressive responses to the mobilizations of the late 1960s and early 1970s. For its analysis, I consider the articulation between the general provisions established by national laws, decrees and regulations and the application of such norms in Rosario, under the jurisdiction of the II Army Corps.
\end{abstract}

Keywords: War councils - Camarón - Social protest - Repression.

Recibido: 24/09/2019

Evaluación: 28/10/2019

Aceptado: 05/11/2019

Anuario de la Escuela de Historia Virtual - Año 10 - № 16 - 2019: pp. 56-70.

ISSN: 1853-7049

http://revistas.unc.edu.ar/index.php/anuariohistoria 


\section{De los consejos de guerra al Camarón. Respuestas represivas a las protestas sociales (1969-1973)}

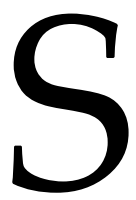

i bien la dictadura de la "Revolución Argentina" comenzó tres años antes, el año 1969 fue un año bisagra por las movilizaciones callejeras que se produjeron en varias ciudades del país. La más conocida fue el Cordobazo, pero también ocurrieron los Rosariazos de mayo y septiembre, entre otras. Al mismo tiempo, las respuestas que generaron estas protestas se enmarcaron en un complejo dispositivo represivo que, sin ser totalmente nuevo, se profundizó a partir de este momento.

Como sostiene Águila (2017, p. 102), la dictadura:

“[...] se desenvolvió en un momento de cambios significativos en el escenario político y social argentino. Durante los años 60, el proceso de modernización económica e industrial se amplificó, articulándose con un clima de contestación social generalizada que impregnó la vida política durante gran parte de la década y que no fue ajeno al contexto internacional y latinoamericano, favorable al ascenso de los movimientos y experiencias insurreccionales y/o revolucionarias. [...] A partir del año 1969, la dictadura comenzó a ser amenazada por protestas sociales y políticas que incluyeron actores, demandas y repertorios de acción variados y novedosos en sus contenidos y formas: la activación de los trabajadores, dotados de nuevas direcciones con carácter antiburocrático y clasista, la creciente agitación entre los sectores medios y universitarios y, finalmente, el surgimiento de las organizaciones político-militares. Estas protestas pueden ser consideradas como el inicio de un período de creciente movilización y contestación social pero además como el comienzo de la intensificación de la represión".

La escalada represiva fue acompañada de la implementación gradual y progresiva de una legislación cada vez más severa que sirvió como instrumento legal para las acciones concretas. La agudización del conflicto social se verificó además en el aumento de la cantidad de presos políticos en el periodo 1969-1973. Inclusive, una parte de esa actividad represiva adoptó un carácter clandestino a través de algunas operaciones desplegadas por los servicios de inteligencia y los grupos paraestatales, llevando adelante amenazas, atentados, secuestros, desapariciones y asesinatos.

De esta manera, para finales de los '60 los militares argentinos, a pesar de haber llegado al poder por la fuerza, se preocuparon por encuadrar sus actos en un marco de legalidad. Como sostiene Anthony Pereira (2010), todos los regímenes dictatoriales del Cono Sur tuvieron, por un lado, una esfera de terror estatal extrajudicial y, por otro, una esfera legal de rutina bien establecida. A su juicio, existió una zona gris donde los gobiernos militares trataron de legalizar la represión por medio de cambios constitucionales; purgas, reorganización y manipulación del Poder Judicial; y promulgación de nuevas leyes y decretos. Asimismo, el autor sostiene que otra táctica utilizada fue la "política de la justicia", es decir, procesos llevados a cabo en los tribunales contra los opositores a los regímenes acusados de crímenes contra la defensa nacional. Esto tenía como objetivo otorgar legalidad a una parte de la represión 
practicada por los gobiernos dictatoriales. Aun así, cuán extendida estaba -o aparentaba estar - esa legalidad era bastante variable en los distintos países y en los diferentes periodos dictatoriales. En este sentido, el gobierno militar de la "Revolución Argentina" consideraba que los tiempos de la justicia ordinaria eran demasiado lentos y que las garantías procesales para los detenidos eran excesivas. Esto llevó a la realización de consejos de guerra que fueron utilizados para juzgar en forma sumaria a detenidos civiles y, en 1971, a la creación de un nuevo tribunal judicial ad hoc para juzgar las "actividades extremistas": la Cámara Federal en lo Penal de la Nación (CFPN), más conocida como el "Camarón".

En este artículo me centro en esos mecanismos "legales" que utilizó la dictadura: los consejos de guerra y el "Camarón", examinando ambos dispositivos utilizados como respuestas represivas a las movilizaciones de fines de los años sesenta y principios de los setenta. Para su análisis, considero la articulación entre las disposiciones generales establecidas por leyes, decretos y reglamentos nacionales y la aplicación de dichas normas en Rosario, bajo jurisdicción del II Cuerpo de Ejército.

\section{El auge de las protestas sociales}

Las grandes luchas que trabajadores y estudiantes desarrollaron en las principales ciudades del interior del país en el año 1969 han sido recordadas popularmente con el sufijo "azos". La más conocida fue el "Cordobazo", ocurrida entre el 29 y 30 mayo de ese año, a partir de la cual las Fuerzas Armadas (FFAA) ordenaron la ocupación militar de la provincia de Córdoba y designaron al Gral. Eric Carcagno como interventor, quien inmediatamente comenzó a reprimir la insurrección.

En la ciudad de Rosario, la reacción popular se expresó bajo la forma de levantamientos urbanos masivos expresados en dos grandes movilizaciones conocidas posteriormente como los Rosariazos. El Primer Rosariazo se produjo en el mes de mayo, unos días antes del Cordobazo. La lucha del movimiento estudiantil comenzó en las ciudades de Resistencia y Corrientes, tras la decisión del rector de la Universidad Nacional del Nordeste (UNNE), Carlos Walker, de aumentar en más del 100\% el valor del comedor universitario. La medida fue repudiada en una marcha en la que, en el marco de acciones represivas, fue asesinado el estudiante Juan José Cabral. En Rosario, el 17 de mayo, unos cuatrocientos estudiantes se reunieron frente al comedor estudiantil, repartieron volantes e hicieron explotar algunas bombas de estruendo que merecieron la atención de la policía, que los reprimió enérgicamente. Allí, perdió la vida el estudiante de Ciencias Económicas Andrés Bello, ${ }^{1}$ generándose automáticamente una importante movilización de repudio en amplios sectores de la sociedad, donde fue asesinado por la policía el obrero y estudiante Luis Norberto Blanco. Al día siguiente, el 22 de mayo de 1969, en la Marcha del Silencio más de 7.000 personas acompañaron al féretro de Blanco en su procesión hacia el cementerio (Ceruti y Sellares, 2002).

\footnotetext{
${ }^{1}$ El Colegio de Abogados emitió un comunicado exigiendo que se tomen las medidas correspondientes al esclarecimiento del crimen del estudiante Bello. En los siguientes días de mayo, se sucedieron actos relámpagos, concentraciones, marchas del silencio, denuncias de testigos, de abogados y comenzó a funcionar una olla popular montada por la CGT de los Argentinos.
}

Anuario de la Escuela de Historia Virtual - Año 10 - N 16 - 2019: pp. 56-70. ISSN: 1853-7049 
Con la intervención militar se establecía el funcionamiento de los consejos de guerra. El cuerpo de asesores jurídicos de la CGT de los Argentinos (GCTA) ${ }^{2}$ emitió un comunicado declarando ilegal la intervención de los consejos de guerra, exigiendo la libertad y solicitando al Consejo Supremo de las FFAA que juzgase y sancione al General Fonseca $^{3}$ (Sagen Gil, 2005).

En el mes de septiembre se produjo el segundo episodio de conflictividad social en Rosario, en el marco de una huelga ferroviaria y un paro activo convocado por la CGT, ${ }^{4}$ conocido como el Rosariazo o el Segundo Rosariazo. El 8 de setiembre de 1969, los obreros de la Unión Ferroviaria pertenecientes a los talleres ferroviarios de Pérez y Villa Diego, realizaron un paro de brazos caídos por la suspensión del delegado administrativo Mario Horat, motivada por la adhesión a varios paros nacionales. Dos días después, "[...] en la Facultad de Medicina se reunió una multitud estudiantil, junto a una delegación de obreros ferroviarios, el ex delegado de la CGT de los Argentinos Héctor Quagliaro y Rosa Trumper de Ingallinela de la Liga de los Derechos del Hombre y colocaron placas recordatorias a Pampillón, Cabral, Blanco y Bello" (Sagen Gil, 2005, p. 82). Se produjeron movilizaciones de trabajadores y estudiantes por varios días, a las que se agregaron barricadas, incendios localizados, ataques a instalaciones ferroviarias, comercios y bancos, que fueron nuevamente reprimidas por un enorme operativo policial, al que debió sumarse Gendarmería Nacional para proteger las propiedades ferroviarias. También se les hicieron consejos de guerra en forma sumaria a los detenidos. ${ }^{5}$

Desbordada la policía, comenzó a actuar la Gendarmería y finalmente el Ejército, trasladando incluso una agrupación militar de combate como un ejército de ocupación. Según el general Alejandro A. Lanusse (1977), hasta ese momento y en concordancia con lo contenido en la legislación de defensa, la doctrina militar establecía una gradación en lo referido al empleo de medios: primero debían utilizarse los efectivos policiales; si estos resultaban insuficientes, los efectivos de seguridad; y en el caso de que unos y otros no alcanzaran a controlar la situación, debían ser empeñadas las FFAA. El miércoles 17 de septiembre de 1969 se hizo una conferencia de prensa en la estación ferroviaria Rosario Norte, en la cual el por entonces coronel Leopoldo F. Galtieri, jefe de la plana mayor de la Agrupación de Combate "G", y Herberto Robinson, 2do Comandante del Comando del II Cuerpo de Ejército, informaron que dicha agrupación militar de combate había

\footnotetext{
${ }^{2}$ En el Congreso Normalizador de la CGT 'Amado Olmos', celebrado entre el 28 y 30 de marzo de 1968 para elegir autoridades de la Confederación (acéfala desde 1967), resultó electo Raimundo Ongaro. Dicha elección y congreso fueron impugnados por un grupo de sindicatos que conducía Augusto Vandor y eligió otra dirigencia encabezada por Vicente Roqué; estos últimos conservaron la sede oficial de la Confederación en Capital Federal situada en la calle Azopardo, mientras que la otra vertiente estableció una organización paralela a la cual denominaron CGT de los Argentinos o del Paseo Colón, haciendo referencia a la ubicación de su sede. Esta central paralela estaba conducida por Ongaro. Un mes más tarde, en un plenario de 27 gremios presidido por Héctor Quagliaro, se formó la CGT de los Argentinos Regional Rosario.

${ }^{3}$ Roberto Aníbal Fonseca fue Comandante del II Cuerpo de Ejército desde el 18 de diciembre de 1967 al 24 de noviembre de 1970 .

${ }^{4}$ Entre ambos acontecimientos se produjo la unificación de la CGT. El 23 de mayo se realizó un plenario intersindical en Buenos Aires, al que acudieron gremios que representaban a las dos centrales sindicales. En esta reunión plenaria se resolvió anular las divisiones existentes, dándose lugar a la unificación del movimiento obrero organizado sindicalmente dentro de una sola CGT. Para dicha ocasión, la CGT de los Argentinos de Rosario envió delegados a la Capital Federal para reclamar a las dos centrales obreras que superaran las diferencias y se sentaran las bases de la unidad de acción (Viano, 2000).

${ }^{5}$ Para más información sobre los Rosariazos, ver: Rosas (2019).
}

Anuario de la Escuela de Historia Virtual - Año 10 - Nº 16 - 2019: pp. 56-70. ISSN: 1853-7049 
60 I De los consejos de guerra al Camarón...

ocupado los objetivos ferroviarios en reemplazo de Gendarmería Nacional (González, Gigena y Shapiro, 2008).

Además de los Rosariazos y el Cordobazo, por entonces se produjo el asesinato del sindicalista Augusto Vandor en junio de 1969; el secuestro y posterior muerte del general Pedro Eugenio Aramburu, un año después, y el creciente desarrollo de la movilización obrera y de las organizaciones político-militares. En ese contexto, el gobierno reforzó la legislación represiva. ${ }^{6}$ Asimismo, ese período estuvo caracterizado por una creciente activación de las organizaciones armadas, ${ }^{7}$ en particular del Ejército Revolucionario del Pueblo (ERP); $;$ las Fuerzas Armadas Peronistas (FAP); 9 las Fuerzas Armadas Revolucionarias (FAR $)^{10} \mathrm{y}$, poco más adelante, Montoneros. ${ }^{11}$

Como consecuencia de estos sucesos, Onganía fue desplazado del gobierno en junio de 1970 y comenzó lo que algunos llaman un "gobierno de transición", ya que la máxima figura política del Ejército seguía siendo el general Lanusse. Fue nombrado presidente el general Roberto Levingston, hasta que la Junta de Comandantes le pidió la renuncia el 23 de marzo de 1971 y, finalmente, fue sucedido por el propio Lanusse.

\section{Los consejos de guerra}

Los consejos de guerra realizados a civiles fueron una práctica represiva que venía siendo utilizada por las FFAA al menos desde 1955,12 donde los ciudadanos acusados de trasgredir las reglas políticas eran procesados y la mayoría de las veces condenados en juicios castrenses. Fueron un mecanismo más del complejo dispositivo represivo que comenzó a agudizarse a partir de las movilizaciones de fines de los años sesenta.

\footnotetext{
${ }^{6}$ Se implantó el estado de sitio, por la ley 18.262, del 30 de junio de 1969 y estuvo vigente hasta mayo de 1973. Se realizaron distintas modificaciones al Código Penal como la inclusión de la pena de muerte, por ley 18.701, de junio de 1970. Se crearon nuevas instituciones para el control y la represión de la protesta social.

${ }^{7}$ Con anterioridad, a principios de la década del '60 habían surgido las Fuerzas Argentinas de Liberación (FAL) de orientación marxista-leninista.

${ }^{8}$ Creado en 1970 como brazo armado del Partido Revolucionario de los Trabajadores (PRT), hasta el año 1973 el ERP fue la principal organización guerrillera del país, por su capacidad operativa y la intensidad de su actividad de propaganda armada.

${ }_{9}^{9}$ Organización de militancia armada, dirigida por Envar El Kadri (dirigente peronista que en su juventud había participado de la resistencia peronista), que en el ‘68 produjo el intento de sublevación de Taco Ralo con el fin de generar un movimiento armado que extendiera la lucha revolucionaria en toda la sociedad al estilo de la teoría del foco. La organización de superficie de las FAP fue el Peronismo de Base (PB). En la década del 70 se produjeron una serie de resquebrajamientos internos que llevaron a que pierda poder.

${ }^{10}$ Las FAR, grupo armado de vertiente marxista, fue producto, en parte, de una escisión de la juventud del Partido Comunista. Si bien venía gestándose desde una etapa previa, hizo su aparición pública en 1970 con la toma de Garín, un pueblo del Gran Buenos Aires. Desarrollaron resonantes acciones entre 1969 y 1971 y se embarcaron en 1972 en un acelerado proceso de peronización, que culminó en octubre de 1973 en una fusión con Montoneros.

${ }^{11}$ La organización armada Montoneros se presentó ante la sociedad el 1 de junio de 1970 mediante el secuestro del general Pedro Eugenio Aramburu. Autodefinidos en sus comienzos como una vanguardia armada nacionalista, católica y peronista, con elementos del marxismo latinoamericano revolucionario, fue la organización político militar peronista más importante.

${ }^{12}$ Sobre la realización de consejos de guerra a civiles realizados en otros momentos históricos de los abordados aquí, ver: Scocco (2016).
}

Anuario de la Escuela de Historia Virtual - Año 10 - N 16 - 2019: pp. 56-70. ISSN: 1853-7049 
La primera vez que se aplicaron consejos de guerra a civiles luego de la reestructuración del Ejército iniciada en $1963,{ }^{13}$ fue en las mencionadas luchas que trabajadores y estudiantes desarrollaron en las principales ciudades del interior del país en el año 1969. Ante estas movilizaciones populares, se determinó ${ }^{14}$ que quedarían sometidas a tribunales militares las personas que incurrieran en determinados delitos, aunque fueran civiles, y que tal juzgamiento estaría a cargo de los consejos de guerra especiales previstos por el artículo 45 del Código de Justicia Militar, en todo el territorio nacional. Un tratamiento especial tuvo la provincia de Córdoba, en virtud de lo prescripto por el decreto $2851,{ }^{15}$ ya que fueron realizados consejos de guerra a conocidos dirigentes gremiales, entre ellos, Agustín Tosco. ${ }^{16}$ Dicho decreto era exclusivo del III Cuerpo de Ejército, con asiento en Córdoba, y lo facultaba para constituir consejos según la ley antes mencionada. Sin embargo, en los días previos se registró un antecedente en Rosario en ocasión del "Primer Rosariazo".

En dicha ciudad, luego de que las fuerzas policiales fueran sobrepasadas en la Marcha del Silencio del 21 de mayo, en la madrugada del 22, el Comandante en Jefe del Ejército, Alejandro A. Lanusse, ordenó la declaración de Zona de Emergencia bajo jurisdicción militar para Rosario y sus alrededores. Como lo consignó el Libro Histórico del II Cuerpo de Ejército con asiento en Rosario, el 22 de mayo de 1969: "Por decreto No 2543/69 del Poder Ejecutivo Nacional, se declara 'Zona de Emergencia' a la Guarnición 'Rosario', por tal motivo se procedió a efectuar los Bandos Militares 1 y $2{ }^{\prime \prime} .{ }^{17}$ Además, el decreto $\mathrm{N}^{\circ}$ 2543 establecía que el por entonces Comandante del II Cuerpo, general Roberto Fonseca, quedaba a cargo de la ocupación militar y que los organismos de gobierno nacional, provincial y municipal quedaban subordinados al Comandante. También asignaba a la Zona de Emergencia determinado personal y recursos. ${ }^{18}$

El Código de Justicia Militar en su Capítulo V, art. 131, ya disponía que: “Durante el estado de guerra, en las zonas de operaciones y zonas de guerra, podrán dictarse bandos destinados a proveer a la seguridad de las tropas y materiales, al mejor éxito de las operaciones, y a establecer la policía en dichas zonas". ${ }^{19} \mathrm{Y}$ el reglamento de asuntos civiles del Ejército de 1966 ampliaba las competencias de los bandos, estableciendo que, si bien los delitos comunes serían de competencia de la justicia civil, podrían "dictarse bandos destinados a proporcionar seguridad a las tropas y a la población civil. Los mismos determinarán las infracciones y las penas que sancionarán su comisión, basadas en el Código de Justicia Militar y en las leyes civiles". ${ }^{20}$ Además, los bandos debían ser publicados para el conocimiento de las tropas y de la población, "cuando prevengan delitos o faltas a cometer por civiles" ${ }^{21} \mathrm{El}$ mencionado decreto facultaba al Comandante

\footnotetext{
${ }^{13}$ Archivo General del Ejército, Ejército Argentino (1963), Comisión Especial de Reestructuración del Ejército, Proyecto sobre el sistema orgánico funcional de Justicia Militar, SXX-044, Colección estructura y organización.

14 Por Ley 18.232, Boletín Oficial de la República Argentina, N. ${ }^{\circ} 21.694$, Buenos Aires, 30/05/1969, p. 2.

${ }_{15}$ Decreto 2851, Boletín Oficial de la República Argentina, N²1.700, Buenos Aires, 10/06/1969, p. 2.

${ }^{16}$ AGN, Archivo Histórico de la Justicia Militar - Depto. Archivo Intermedio. Carpeta 10.117. Caja 1. Serie: Antecedentes.

${ }^{17}$ Libro Histórico del II Cuerpo de Ejército, 1969, p. 28. El3 de junio se produjo el cese de la "zona de emergencia" y se dejó sin efecto el decreto citado.

${ }^{18}$ Decreto No 2543, Boletín Oficial de la República Argentina, N²1.707, 19/06/1969, p. 6.

${ }^{19}$ Ley No 14.029, Boletín Oficial de la República Argentina, N 16.958, cit., p. 5.

${ }^{20}$ Ejército Argentino (1966), RC-19-1. Reglamento de operaciones de asuntos civiles, p. 98.

${ }^{21}$ Ibídem.
}

Anuario de la Escuela de Historia Virtual - Año 10 - N 16 - 2019: pp. 56-70. ISSN: 1853-7049 
a dictar bandos si la situación lo requería. El Bando Militar $\mathrm{N}^{\circ} 1$ anunciaba la aplicación de la justicia militar. Se proclamaba la utilización de los medios necesarios:

“[...] para una represión rápida, enérgica y eficaz de los actos delictivos que se cometan aprovechando la conmoción existente; que para esa finalidad se debe establecer la vigencia de los procedimientos expeditivos previstos en el Código de Justicia Militar. [...] toda persona o conjunto de personas [...] que ataque a personal militar o de las fuerzas de seguridad, será juzgada por la justicia militar y condenada a prisión o reclusión de uno a quince años. Si del ataque resultara la muerte del ofendido, la pena será la establecida en las disposiciones pertinentes del Código de Justicia Militar. [...] Las fuerzas encargadas de garantizar el orden podrán usar sus armas sobre personas sorprendidas infraganti en la comisión de los delitos previstos" (González, Gigena y Shapiro, 2008, p. 65).

De acuerdo al Libro Histórico del II Cuerpo, el 23 de mayo se formó el Consejo de Guerra Especial, “en razón de las exigencias que impuso la declaración de 'Zona de Emergencia', a los efectos del juzgamiento de las infracciones sujetas a la Justicia Militar como consecuencia de los Bandos Militares dictados". ${ }^{22}$

En el mes de septiembre se produjo el segundo episodio de conflictividad social con el "Segundo Rosariazo". En dicha oportunidad, el Poder Ejecutivo ordenó por decreto $N^{\circ} 5.324$ la aplicación de la ley de Defensa Civil. Los ferroviarios en huelga fueron sometidos al Código de Justicia Militar, haciéndose excepcionalmente una distinción por sexo y edad: "Art. $7^{\circ}$ - El personal masculino convocado, mayor de 18 años, queda sometido a las disposiciones del Código de Justicia Militar [...] El personal femenino, cualquiera sea su edad, y el personal masculino menor de 18 años, convocado, que cometieran delitos, serán juzgados por los Tribunales de la Justicia Ordinaria". ${ }^{23}$ De esta forma, aunque la celebración de consejos de guerra destinados a la población civil no fue una práctica que comenzó con los "azos", sino que data al menos de los años 50 del siglo XX, la legislación represiva fue incrementándose gradualmente a partir del año 1969, dotando de herramientas al aparato de justicia militar que desembocaron y se condensaron luego en la última dictadura militar (1976-1983). ${ }^{24}$

\section{Los presos políticos}

A partir de 1969, la legislación represiva fue aumentando gradualmente de manera considerable. En junio de 1971 fue dictada la Ley 19.081, conocida como de "represión del terrorismo y la subversión", que autorizaba a requerir la colaboración de las FFAA a fin de "prevenir y combatir la subversión interna, el terrorismo y demás hechos conexos"

\footnotetext{
${ }^{22}$ Libro Histórico del II Cuerpo de Ejército, 1969, p. 28. Beba y Beatriz Balvé (1985, p. 53) sostienen una versión que afirma que el Tribunal Militar encargado de los Consejos de Guerra fue presidido en principio por el Tte. Cnel. Ledesma. Este habría pedido ser relevado de su cargo porque "en mis funciones no entra juzgar personas honestas". Fonseca le habría respondido: “Usted Teniente Coronel tiene dos caminos, o preside el Tribunal o se pega un tiro". El Tte. Cnel. Ledesma habría sido intervenido quirúrgicamente por una bala que penetró su cabeza con orificio de entrada en el entrecejo. Sin embargo, no he encontrado documentación que sustente esta información.

${ }^{23}$ Decreto $N^{\circ} 5324$, Boletín Oficial de la República Argentina, № 21.791, Buenos Aires, 20/10/1969, p. 3.

${ }^{24}$ Para la realización de consejos de guerra en la última dictadura militar ver D' Antonio (2016) y Scocco (2016).
} 
y que colocaba a las fuerzas policiales bajo el control operacional del respectivo cuerpo de Ejército. Por otra parte, fue creada por Ley 19.053 la Cámara Federal en lo Penal de la Nación (CFPN), un fuero exclusivo para juzgar delitos de "naturaleza subversiva", que veremos más adelante. El 20 de abril de 1972 mediante la Ley 19.582 se fijó el régimen para el cumplimiento de medidas cautelares de carácter personal con la comisión de delitos subversivos y ese mismo día se publicó la Ley 19.583, que disponía normas para agilizar la instrucción de sumarios iniciados a raíz de delitos subversivos. Cuatro días después, el 24 de abril de 1972, la Ley 19.598 establecía el control de la FFAA sobre unidades carcelarias en la que se hallaban detenidos, procesados o condenados por hechos subversivos (Eliaschev, 2011).

Como sostiene Eidelman (2010):

“Desde abril de 1972 las cárceles que albergaban presos políticos fueron puestas bajo control operacional de las Fuerzas Armadas por ley 19.594 y a fines de setiembre se aprobó un reglamento de detenidos de máxima peligrosidad, ley 19.863, para el penal de Rawson, la cárcel de Villa Devoto, el buque Granaderos y el penal de Villa Urquiza, en Tucumán. (p. 119)".

Finalmente, la Ley 20.032, de diciembre de 1972, modificó la Ley 19.081, facultando al Poder Ejecutivo Nacional (PEN) a emplear las FFAA a fin de prevenir y combatir la subversión interna y el terrorismo (Águila, 2017).

El ejercicio de la represión excedió a las organizaciones armadas y se desplegó contra aquellos sectores que participaban en la protesta social y en la solidaridad y defensa de presos políticos, combinando acciones que se pretendían sujetas a derecho con violentas intervenciones que escapaban a cualquier marco de legalidad. Ejemplo de ello son los asesinatos de manifestantes; las detenciones masivas a disposición del PEN sin causa judicial; la generalización del uso de la tortura en las instituciones policiales y militares y los secuestros y desapariciones que, cabe aclarar, todavía eran casos aislados.

Según Eidelman (2010, p. 176): "Solo entre 1966 y 1970, durante el gobierno de Onganía, se consideraba que habían pasado por las cárceles del país unos 16 mil detenidos por motivos políticos. Algunas estimaciones de la época calculaban unas 25 mil detenciones entre 1969 y 1972". Por su parte, la población carcelaria de la provincia de Santa Fe, al 10 de diciembre de 1972, era de 701 procesados y 827 condenados, lo que significaba un total de 1.528 detenidos alojados en la jurisdicción santafesina. ${ }^{25}$

En Rosario, Juan Carlos Sánchez asumió la jefatura del Comando del II Cuerpo el 24 de noviembre de 1970 y la Unidad Regional II de la policía estuvo a cargo del Comandante retirado de Gendarmería Agustín Feced ${ }^{26}$ desde comienzos de ese año. Cuando Sánchez ocupó la comandancia del II Cuerpo, planificó con Feced las

\footnotetext{
${ }_{25}$ Según cuadro confeccionado por el autor en base a información publicada en Revista Penal y Penitenciaria, la revista del Servicio Penitenciario Federal, tomo XXX, 1971-1973 (Eidelman, 2010, p. 309).

${ }^{26}$ Agustín Feced fue Comandante Mayor de Gendarmería hasta 1969. Según Carlos Del Frade (2000), comenzó su "lucha contra la subversión" en noviembre de 1960, cuando comandó una docena de hombres que reconquistaron el Regimiento 11 de Infantería tomado por la resistencia peronista. Su segunda aparición en la represión fue en noviembre de 1969 en el marco del Rosariazo como encargado de un Batallón en Corrientes. Fue designado Jefe de Policía de la Unidad Regional II de Rosario a comienzos de 1970 hasta 1972. También estuvo involucrado en la investigación por el asesinato de Sánchez, ocurrido en abril de 1972. El 8 de abril de 1976, Feced asumió nuevamente como Jefe de Policía de Rosario. Se mantuvo en ese cargo hasta mayo 1978. Para la toma del Regimiento 11 de Infantería, ver: Scocco y Divinzenso (2017).
}

Anuario de la Escuela de Historia Virtual - Año 10 - N 16 - 2019: pp. 56-70. ISSN: 1853-7049 
64 | De los consejos de guerra al Camarón...

operaciones "contrainsurgentes". Distintos abogados de diversos partidos políticos acusaron a Sánchez y Feced de haber secuestrado y torturado, entre 1971 y principios de 1972, a más de cien estudiantes, obreros y militantes cristianos de base (Del Frade, 2004). De esta forma, en el plano local, el año 1971 representó un significativo aumento del número de detenidos en dependencias policiales y cárceles que fueron puestos a disposición del Comando del II Cuerpo de Ejército. ${ }^{27}$ Se produjo así una militarización de los espacios carcelarios, como sucedió en la Unidad de Detenidos № 3, Cárcel de Encausados, donde eran destinados los varones, que tenía una denominada zona o pabellón militar y era custodiado por la Gendarmería Nacional ${ }^{28}$ y en la delegación de la Policía Federal de Rosario o en la Alcaldía de Mujeres. ${ }^{29}$

Se implantaba así en Rosario el método represivo que comenzaba con la detención o el secuestro por parte de fuerzas de seguridad. Luego, el detenido era trasladado a un lugar en el que se lo torturaba para obtener información, la mayoría de las veces a la Jefatura de la Policía provincial o a la Policía Federal. Finalmente, era reconocido ante un juez y trasladado a alguna dependencia carcelaria. En algunos casos, las declaraciones obtenidas bajo tortura fueron consideradas válidas por los jueces intervinientes. Los detenidos realizaron las denuncias por apremios ilegales ante estos jueces, aunque la mayor parte de las veces fueron ignoradas.

Una de las características más importantes de este periodo (1969-1973) fue el comienzo de los secuestros o detenciones selectivos de militantes de las organizaciones de la izquierda armada y no armada y personas vinculadas a ellas, situación que continuó en los años posteriores. La estrategia de las fuerzas de seguridad no apuntaba a la desaparición de personas en sí misma, sino a la obtención de información y a la desarticulación de las organizaciones político-militares de la época. El uso extendido de la tortura hacia los detenidos podía ocasionar que la persona muriera durante las sesiones de tortura y, ante esto, las fuerzas intervinientes desaparecían el cuerpo para eliminar las evidencias.

Un aspecto central de la experiencia represiva fue la institucionalización del secuestro. Como sostiene Eidelman (2010, p. 131):

"A diferencia de la experiencia posterior, la metodología aplicada por el aparato represivo en esos años no parece haber sido el secuestro para la desaparición, sino la utilización de una extrema discrecionalidad para transformar detenciones en secuestros, secuestros en detenciones y la posibilidad de hacer desaparecer el cadáver en los casos en que la víctima muriera durante las sesiones de tortura, de forma de ocultar con el cuerpo la prueba del asesinato. También existía una garantía de protección e impunidad para los agentes del Estado comprometidos directamente con esas prácticas".

\footnotetext{
${ }^{27}$ Las detenciones fueron respaldadas por la justicia federal y/o la CFPN. Dichas instancias judiciales se ocuparon de procesar, y en algunos casos condenar, por infracción a las distintas leyes antisubversivas a los detenidos por las fuerzas de seguridad (Águila, 2017).

${ }^{28}$ En junio de 1972 el Foro de Buenos Aires por la Vigencia de los Derechos Humanos le dedicó una página a la descripción del régimen carcelario de este penal, al que calificaba de "infrahumano". Las celdas individuales eran pequeñas, frías y húmedas. Los presos no podían hablar entre sí, tenían solo dos visitas semanales de 15 minutos sin contacto, contaban con pocos elementos y no podían ingresar libros. Las audiencias con los abogados defensores eran escasas y debían efectuarse en presencia de un oficial del Ejército. Foro de Buenos Aires por la Vigencia de los Derechos Humanos, Boletín Nº Buenos Aires, junio de 1972. 29 “Denuncia OSPPEG torturas a presos”, El Litoral, Santa Fe, 26/01/1972.
}

Anuario de la Escuela de Historia Virtual - Año 10 - N 16 - 2019: pp. 56-70. ISSN: 1853-7049 
Si bien la tortura era una práctica antigua, entre fines de la década del ‘ 60 y principios de la del '70 su uso se generalizó. Como legalmente se podía mantener a un detenido incomunicado durante cinco a diez días, plazo que en muchos casos era superado, en general ese tiempo era utilizado para que las marcas más evidentes de la tortura en los cuerpos se atenuaran, antes de que el detenido pudiera entrar en contacto con su abogado y con el juez, si no estaba a disposición del PEN.

\section{El Camarón}

El 28 de mayo de 1971 el gobierno militar creó, bajo la Ley 19.053, un nuevo tribunal judicial ad hoc para juzgar las "actividades extremistas": la Cámara Federal en lo Penal de la Nación (CFPN), con sede en Capital Federal, aunque contaba con competencia territorial en todo el país, conocida como "fuero antisubversivo", "Camarón" o "Cámara del Terror". Buscaba brindar una cobertura de legalidad a la actividad represiva del Estado con mayor celeridad. Los juicios de la CFPN eran orales y sus resoluciones eran inapelables; es decir, no existía una doble instancia, esto es, un tribunal superior al cual se pudiese recurrir en caso de considerar que algún derecho había sido violado (Sarrabayrouse Oliveira, 2016).

Antes de la creación del Camarón, se habían realizado varios juicios importantes contra miembros de las organizaciones político-militares, así como diferentes consejos de guerra que fueron utilizados en distintos momentos para juzgar en forma sumaria detenidos civiles. Según D’ Antonio y Eidelman (2016, pp. 81-82): “La iniciativa de crear en el seno del aparato judicial un tribunal especial que concentrase el juzgamiento de la actividad de la guerrilla y la izquierda fue una propuesta cuyo propósito era evitar la utilización generalizada de los tribunales militares para juzgar a civiles en un contexto de fuerte impugnación al gobierno por parte de diferentes sectores". En menos de dos años, esa cámara penal desarrolló una gran actividad procesando y encarcelando a cientos de personas y concentrando en sus manos la mayoría de las causas penales vinculadas a la represión de la actividad política de la izquierda y, en particular, de las organizaciones político-militares. ${ }^{30}$

En Rosario, la mayoría de los fallos fueron para militantes de las FAR y del ERP. ${ }^{31} \mathrm{La}$ CFPN intervino en casos de fuerte repercusión pública durante el año 1972 como fue el asesinato del jefe del Comando del II Cuerpo del Ejército, teniente general Juan Carlos Sánchez, en la ciudad de Rosario, a manos de un comando conjunto de las FAR y el

30 “La CFPN desarrolló una gran actividad, con miles de detenidos en varias cárceles del país, procesando a varios cientos de personas y generando muchas condenas. Según uno de los jueces que integró la CFPN, Jaime Smart, en toda su actividad llegó a dictar 600 sentencias condenatorias y en el momento de su disolución tenía unos 500 procesados". Ver el testimonio de Smart en Vigo Leguizamón (2001, p. 90) citado en Eidelman (2010, p.198).

${ }^{31}$ Se dictaron numerosas condenas por robo y por un asalto a un camión de un frigorífico y sustracción de mercaderías, realizado por un comando del ERP, el 17 de marzo de 1971. Un fallo de marzo de 1972 de la Sala 1 del Camarón condenaba por asociación ilícita y robo calificado, a varios militantes del ERP de Rosario. Otra condena por asociación ilícita, calificada por tenencia de armas de fuego, explosivos y compartimentación celular, dictada por la Sala 1 el 2 de mayo de 1972 contra militantes de las FAR de la ciudad de Rosario y que establecía una condena máxima de 7 años. Los datos aquí proporcionados fueron extraídos del trabajo de Eidelman ya citado.

Anuario de la Escuela de Historia Virtual - Año 10 - Nº 16 - 2019: pp. 56-70. ISSN: 1853-7049 
66 | De los consejos de guerra al Camarón...

ERP. ${ }^{32}$ A fines de 1972 comenzó el juicio en la Sala Segunda de la CFPN. El 19 de diciembre tuvo que ser suspendido por algunos incidentes. El fiscal Gabino Salas había solicitado la pena de reclusión perpetua para los cinco imputados, aunque se había comprobado que ninguno de ellos había sido el autor material de los disparos. Los abogados defensores plantearon la inconstitucionalidad del Camarón, a la vez que pidieron la absolución de los detenidos. Calificaron al juicio de "arbitrario", aludiendo que las pruebas que intentaron agregar a la causa y los testigos propuestos por ellos habían sido denegados por los jueces. Ante los sucesivos rechazos, los diez abogados renunciaron a la defensa de los acusados. Gustavo Yofré, padre de una de las imputadas -Gabriela Yofré-, ${ }^{33}$ fue golpeado y detenido ante sus protestas. También fueron detenidos los letrados defensores Gustavo Ruor y Mario Hernández. El resto de los abogados se negó a abandonar el lugar hasta que aquellos fueron dejados en libertad. ${ }^{34}$

Pese a la renuncia de los abogados defensores, el juicio siguió su curso. El 9 de febrero de 1973 se conocieron las condenas.

“En ese juicio se imputó a cinco personas y condenó por homicidio calificado por alevosía, en concurso premeditado en perjuicio de un jefe militar en actividad, con asociación ilícita calificada por uso de armas y organización celular. La condena incluyó 2 reclusiones perpetuas para Gabriela Yofré y Jorge Emilio Reyna, una prisión perpetua para Luis Alejandro Gaitini, partícipe secundario, una condena de 11 años para Graciela Lavalle de Reyna y una última, por 9 años, para Reinaldo Briggiler. La diferencia entre reclusión perpetua y prisión perpetua implicaba al régimen carcelario, el sistema de prescripciones y al cómputo de las penas, siendo la reclusión la más severa" (Eidelman, 2010, pp. 219-220).

Este juicio es interesante para analizar las estrategias desarrolladas en la defensa de presos políticos en la época. La rapidez con la que la CFPN procesaba las acusaciones impedía a los abogados defensores seguir los procedimientos debidos y violaba la garantía de la defensa en juicio. Las estrategias que adoptaron estos letrados se relacionaban explícitamente con los planteos expuestos por el abogado del Frente de Liberación Argelino, Jacques Vergés (1972), que conceptualizaba dos tipos de procedimientos a desplegar en los juicios por razones políticas: los de "connivencia" y los de "ruptura". La estrategia de "connivencia" partía de aceptar el ordenamiento normativo del "sistema" para, dentro de su marco legal, tratar de demostrar, o bien que

32 Producida el 10 de abril de 1972, sucedió por la mañana en una esquina céntrica -Alvear y Córdoba-, a pocas cuadras de la sede del Comando del II Cuerpo y la Jefatura de Policía de Rosario. En el texto donde el ERP y las FAR se atribuyeron la ejecución de Sánchez, hacían referencia "a los operativos rastrillo, en la búsqueda de elementos combatientes", a las acciones para impedir el reparto de víveres y otros elementos expropiados por el ERP, a las muertes de Luis Pujals y Segundo Telésforo Gómez y al maltrato a los presos políticos. Cf. Águila (2017).

${ }_{33}$ Gabriela Yofré, en junio de 1972, acusó al juez Black de negarse a recibir sus denuncias de violación y torturas, según un informe de CoFaPPEG de 1972. CoFaPPEG, Torturas en Argentina, Córdoba, julio de 1972. Nacida en Córdoba un 4 de junio de 1952. Militante de las FAR, compañera de Juan Julio Roqué, brutalmente torturada luego de ser detenida en Rosario el 2 de junio, acusada de integrar el comando que ajustició a Juan Carlos Sánchez el 10 de abril de 1972. Fue liberada por la amnistía presidencial el 25 de mayo de 1973. Luego ingresó a Montoneros. Fue secuestrada y desaparecida por la última dictadura militar, el 28 de octubre de 1976. Baschetti, Roberto Militantes del peronismo revolucionario uno por uno. URL: http://www.robertobaschetti.com/biografia/y/12.html.

34 "Serios incidentes hubo en un juicio a extremistas. Renunciaron masivamente los defensores de los implicados en el asesinato del teniente general Juan Carlos Sánchez", La Capital, 20/12/1972, p 17.

Anuario de la Escuela de Historia Virtual - Año 10 - N 16 - 2019: pp. 56-70. ISSN: 1853-7049 
el imputado no incurrió en el delito del que se lo acusaba, o bien que la figura delictiva creada por el "sistema" entraba en contradicción con los principios generales del derecho por él sustentados. La estrategia de "ruptura", por el contrario, tenía por objeto cuestionar la construcción "ficticia" de la Justicia, denunciando las condiciones en las que funcionaba el sistema jurídico, sus instituciones y actores (Chama, 2010). El juicio de Sánchez fue un típico ejemplo de juicio de ruptura. La ruptura significaba el cuestionamiento del tribunal, de su legitimidad, tanto del tribunal como del derecho aplicable. Rodolfo Mattarollo, abogado defensor e integrante de la Asociación Gremial de Abogados (AGA), ${ }^{35}$ sostenía:

\begin{abstract}
"Nosotros pensábamos que cuando existía la posibilidad de obtener la liberación, una condena leve para un prisionero o procesado, teníamos que agotar todas las posibilidades de lograrlo. Pero había situaciones en las que esto no era posible. Ya la tortura se empleaba en una forma generalizada, sistemática y había situaciones en las que lo único posible era precisamente patear el tablero, por decirlo así. En el juicio de Sánchez los prisioneros habían sido brutalmente torturados y no tenía sentido tratar de jugar con las distintas posibilidades tácticas que puede dar una defensa técnica. Lo único que tenía sentido, a nuestro entender, fue lo que hicimos: retirarnos del juicio porque considerábamos que no estaban dadas las garantías para la defensa, que se habían violado todas las garantías judiciales al utilizar la tortura en la manera en que se lo hizo y abandonamos el lugar, lo cual colocaba en una crisis bastante seria al tribunal porque era un momento en que todavía había un resquicio muy estrecho de legalidad que la dictadura de Lanusse quería preservar". (Testimonio de Rodolfo Mattarollo, Buenos Aires, 2003. Citado en Bacci, Carnovale y Oberti, 2010, p. 23).
\end{abstract}

La mayoría de los abogados defensores en las causas del Camarón eran oriundos de Buenos Aires y estaban vinculados con la AGA, conocida como "la Gremial". Una excepción la presentaba Felipe Rodríguez Araya, ${ }^{36}$ que intervino en varias defensas, especialmente de personas juzgadas por hechos ocurridos en Rosario $u$ oriundas de la ciudad. Una de sus defendidas fue la mencionada Gabriela Yofré. Asimismo, algunos de estos abogados fueron juzgados por la CFPN. En un informe secreto del Servicio de Inteligencia de la Policía de Buenos Aires (SIPBA) cuyo asunto era: "Determinar conexiones de dos abogados con elementos pertenecientes a las F.A.L." , ${ }^{37}$ se sostenía que los abogados, uno detenido y otro prófugo, debían afrontar una causa por “Averiguación Infracción Art. 210 del Código Penal" en la CFPN, el 26 de septiembre de 1972.

\footnotetext{
${ }^{35}$ La Asociación Gremial de Abogados (AGA), gestada a mediados de 1971, se conformó en contraposición con los organismos profesionales que agrupaban a los abogados la Capital Federal, que se negaban a asumir la actividad defensiva, como el Colegio de Abogados o la Asociación de Abogados de Buenos Aires (Chama, 2010).

${ }^{36}$ Felipe Rodríguez Araya nació el 9 de mayo de 1934, en Ricardone, provincia de Santa Fe. Era hijo de un prestigioso dirigente radical, Agustín Rodríguez Araya, quien había sido diputado nacional y que se tuvo que exiliar en Uruguay en la década del cuarenta. Se graduó de abogado en la Universidad de Buenos Aires, volviendo a vivir a Rosario y a ejercer su profesión. Fue un reconocido abogado con amplia trayectoria en la defensa de presos políticos. Fue secuestrado junto a su colega Luis Lescano por un grupo armado paraestatal y asesinado el 30 de septiembre de 1975.

${ }^{37}$ DIPBA, Mesa Ds, Varios, legajo 526. Informe de la SIPBA. Asunto: “Determinar conexiones de dos abogados con elementos pertenecientes a las F.A.L.", 26/09/1972.
}

Anuario de la Escuela de Historia Virtual - Año 10 - N 16 - 2019: pp. 56-70. ISSN: 1853-7049 
68 I De los consejos de guerra al Camarón...

Sobre los casos de rosarinos donde intervino la CFPN, cabe señalar que el 2 de diciembre de 1972 un grupo de profesionales e instituciones de Rosario convocó a una conferencia de prensa para informar la situación de los presos políticos de la ciudad, recientemente detenidos, procesados y con orden de captura por parte del Camarón. Se denunciaron también los apremios ilegales de los que eran objeto. ${ }^{38} \mathrm{La}$ CFPN fue disuelta el 26 de mayo de 1973, por la Ley $\mathrm{N}^{\circ}$ 20.510, votada por unanimidad en el Congreso Nacional, en el contexto de las primeras medidas del gobierno peronista recién asumido.

\section{A modo de cierre}

En este recorrido podemos advertir cómo la institucionalización de la represión, que fue implementada gradualmente desde mediados de los años ' 50 , tuvo un momento bisagra a partir de la represión a las movilizaciones callejeras de 1969, profundizándose en los años siguientes frente al aumento de la cantidad de los presos políticos, mediante una estricta legislación que no dejaba como letra muerta lo regulado hasta el momento, sino que lo ampliaba y lo complementaba. En este sentido, comenzando con la utilización de los consejos de guerra para juzgar a civiles acusados de "actividades subversivas", finalmente se creó un tribunal especial, pero civil, que enjuició a las personas incriminadas por los mismos delitos. Ambos dispositivos se fundamentaban en la necesidad de acabar de forma severa, rápida y eficiente con este tipo de actividades, ya que el gobierno militar consideraba que la lentitud y exactitud de la justicia ordinaria impedirían el rigor punitivo y la rapidez que demandaban determinados contextos de conflictividad social.

Estos mecanismos que utilizó la dictadura de la "Revolución Argentina" tienen la característica de haber sido ideados y considerados por las FFAA como "legales". En este sentido, los militares argentinos, a pesar de haber llegado al poder por la fuerza, se preocuparon por encuadrar sus actos en un marco de legalidad, dentro de una escala represiva que comenzó a profundizarse como respuesta a las protestas sociales de 1969 y alcanzó su punto máximo en 1972 con detenciones masivas y procesos judiciales sumarios.

\section{Referencias bibliográficas}

Águila, G. (2017). El accionar represivo entre dos dictaduras, 1966-1983. En G. Águila. (Dir.), Territorio Ocupado. La historia del Comando del II Cuerpo de Ejército en Rosario (1960-1990) (pp. 99-206). Rosario: Editorial de la Municipalidad de Rosario.

Bacci, C., Carnovale, V. y Oberti, A. (2010). Abogados, Derecho y Política. Buenos Aires: Memoria Abierta.

Balvé, B. y Balvé, B. (1985). De Protesta y Rebelión: la Subversión (Rosario, mayo 1969). Serie de Estudios $\mathrm{N}^{\circ} 45$, Buenos Aires: Cuadernos del Centro de Investigaciones en Ciencias Sociales (CICSO).

Ceruti, L. y Sellares, M. (2002). La rosa crispada. Revista Los '70, 4, s/pp.

\footnotetext{
${ }^{38}$ Las instituciones convocantes eran el Organismo Único de Arquitectura, la Federación Universitaria Argentina, la Agrupación de Abogados de Rosario (AAR), la Liga Argentina por los Derechos del Hombre (LADH) y el Movimiento contra la Represión y la Tortura. Resolvieron enviar telegramas al presidente de la Nación, el general Alejandro Lanusse, y a la Cámara Federal referidos a la situación de los detenidos por razones políticas y gremiales. "Informan la situación de algunos detenidos", La Capital, 3/12/1972, p. 21.
}

Anuario de la Escuela de Historia Virtual - Año 10 - ํo 16 - 2019: pp. 56-70. ISSN: 1853-7049 
Chama, M. (2010). La defensa de presos políticos a comienzos de los '70: ejercicio profesional, derecho y política. Cuadernos de antropología social, 32, pp. 195-217.

D'Antonio, D. y Eidelman, A. (2018). Poder judicial, represión y violencia política en los setenta: la experiencia del 'Camarón'. En D. D'Antonio (Comp.). Violencia, espionaje y represión estatal. Seis estudios de caso sobre el pasado reciente argentino (pp. 1-26). Buenos Aires: Imago Mundi.

D'Antonio, D. y Eidelman, A. (2016). El fuero antisubversivo y los consejos de guerra contra civiles en la Argentina de los años 70. E.I.A.L., 27 (2), 77-97.

D' Antonio, D. (2016). Los Consejos de Guerra durante la última dictadura militar argentina (1976-1983). Ibero-Americana, 3, 1-18.

Del Frade, C. (2000). El Rosario de Galtieri a Feced. Rosario: Editorial El Eslabón.

Del Frade, C. (2004). Matar para robar, luchar para vivir: historia política de la impunidad, Santa Fe, 1976-2004. Rosario: Ciudad Gótica.

Eidelman, A. (2010). El desarrollo de los aparatos represivos del Estado argentino durante la "Revolución Argentina", 1966-1973 (Tesis de Doctorado). Universidad de Buenos Aires: CABA.

Eliaschev, P. (2011). Los hombres del juicio. Buenos Aires: Sudamericana.

González, O., Gigena, E. y Shapiro, J. (2008). Los rosariazos de 1969. De mayo a septiembre. Rosario: Homo Sapiens Ediciones.

Lanusse, A. (1977). Mi Testimonio. Buenos Aires: Laserre.

Pereira, A. (2010). Ditadura e repressão: o autoritarismo e o Estado de Direito no Brasil, no Chile e na Argentina. São Paulo: Paz e Terra.

Rosas, A. (2019). Los Rosariazos. Un camino vigente. Rosario: Editorial último Recurso.

Sagen Gil, G. (2005). La CGT de los Argentinos en Rosario, 1968-1969. Rosario: Universidad Nacional de Rosario.

Sarrabayrouse Oliveira, M. J. (2016). Familia judicial y dictaduras: la creación del 'fuero antisubversivo' en la década del 70. En G. Águila, S. Garaño, y P. Scatizza (Coord.), Represión estatal y violencia paraestatal en la historia reciente argentina. Nuevos abordajes a 40 años del golpe de Estado (pp. 269-294). La Plata: Facultad de Humanidades y Ciencias de la Educación, Universidad Nacional de La Plata.

Scocco, M. y Divinzenso, A. (2017). Ejército y política: Rosario durante los primeros años del II Cuerpo de Ejército, 1960-1966. En G. Águila (Dir.), Territorio Ocupado. La historia del Comando del II Cuerpo de Ejército en Rosario (1960-1990) (pp. 19-50). Rosario: Editorial de la Municipalidad de Rosario.

Scocco, M. (2016). Los consejos de guerra militares como práctica de represión política (1956-1983). En G. Águila, S. Garaño, y P. Scatizza. (Coord.), Represión estatal y violencia paraestatal en la historia reciente argentina. Nuevos abordajes a 40 años del golpe de Estado (pp. 215-244). La Plata: Facultad de Humanidades y Ciencias de la Educación, Universidad Nacional de La Plata.

Vergés, J. (1972). Estrategias judiciales en los procesos políticos. Madrid: Anagrama. 
70 I De los consejos de guerra al Camarón...

Viano, C. (2000). Una ciudad movilizada (1966-1976). En A. Pla. (Coord.), Rosario en la Historia (de 1930 a nuestros días) Tomo II (pp. 23-119). Rosario: UNR Editora.

Para citar este artículo:

Scocco, Marianela (2019). De los consejos de guerra al Camarón. Respuestas represivas a las protestas sociales (1969-1973). Anuario de la Escuela de Historia Virtual, 16, 56-70. 